\title{
CLINICAL AND PATHOLOGICAL ASPECTS OF SOLITARY SPINAL NEUROFIBROMA
}

\author{
C. SAnguinetti, N. SPeCChia, A. Gigante, L. de Palma, F. GReCo \\ From the Catholic University of the Sacred Heart, Rome and the University of Ancona, Italy
}

Four cases are described of solitary spinal neurofibroma, a rare tumour of the spinal cord or nerve roots. Computerised tomography provided an accurate topographical definition of the tumour. Magnetic resonance imaging showed an increased T2-weighted signal and multiple areas of decreased T1- and T2-weighted signals centrally. The MR signals matched the histological examination which showed hyperplastic interfascicular connective tissue, pleomorphic cells, and tightly packed nerve fibres compressed by the surrounding loose connective tissue. Electron microscopy showed three types of cell: Schwann cells, fibroblast-like cells, and mast cells. The histological findings suggests that solitary spinal neurofibroma is a distinct pathological entity which could be diagnosed preoperatively from the MR images.

J Bone Joint Surg [Br] 1993;75-B: 141-7. Received 14 April 1992; Accepted 22 June 1992

C. Sanguinetti, MD, Professor

N. Specchia, MD, Researcher

A. Gigante, MD, Researcher

L. de Palma, MD, Associate Professor

Institute of Clinical Orthopaedics, Catholic University of the Sacred Heart, Largo Agostino Gemelli 8, 00168 Rome, Italy.

F. Greco, MD, Professor

Department of Orthopaedics, University of Ancona, Largo Cappelli 1, 60100 Ancona, Italy.

Correspondence should be sent to Professor C. Sanguinetti.

(C)1993 British Editorial Society of Bone and Joint Surgery $0301-620 \mathrm{X} / 93 / 1496 \$ 2.00$
Spinal neurofibroma is one of the rarest of the neoplasms involving the spinal cord or roots and occurs much less often than neurinoma, meningioma or glioma (Minckler 1971; Hertzog et al 1980; Enzinger and Weiss 1983; Harkin 1986). It is now recognised, although not universally, as an entity distinct from the more common spinal neurinoma (Sanguinetti, de Santis and Rosa 1981).

The first systematic classification of nerve tumours was that of von Recklinghausen (1882) in the context of phakomatosis, a disorder characterised by disseminated hamartomas of the eye, skin and brain. He introduced the term 'neurofibroma', attributing the histogenesis of this tumour to the endoneurial and perineurial sheaths. Subsequently, all similar lesions, not necessarily related to von Recklinghausen's disease, were grouped under the one term.

In the past many authors have considered neurinoma and neurofibroma to be the same (von Recklinghausen 1882; Adair and McLean 1937; Zülch 1965; Nittner 1976) while others maintained the distinction between them (Verocay 1910; Lhermitte and Leroux 1923; Penfield and Young 1930; Tarlov 1940; Stout 1958; Masson 1968; Catalano, Fanfani and Mazzone 1985; Russell and Rubinstein 1989). There is also controversy as to the cells from which these lesions originate and from these uncertainties there have arisen such terms as schwannoma, peripheral glioma, perineurial fibroblastoma, neurilemmoma, etc (Poirier, Escourolle and Castaigne 1968).

The clinical data and the imaging and macroscopic appearances are rarely sufficient to differentiate between neurinoma and neurofibroma but taking account of the specific histological and ultrastructural differences, most authors now prefer to distinguish between them (Minckler 1971; Enzinger and Weiss 1983; Chomette et al 1984; Okazaki and Scheithauer 1988; Halliday, Sobel and Martuza 1991 ; Sanguinetti et al 1991). In agreement with others (Erlandson and Woodruff 1982; Bouldin 1990), we define spinal neurofibroma as a primary, commonly benign tumour of the spinal cord or nerve roots, which is pathologically different from spinal neurinoma and may be single or multiple.

The current tendency is to separate the single from the multiple lesions, since the latter are related to type 1 von Recklinghausen's disease, just as multiple neurino- 
mas are related to type 2 von Recklinghausen's disease (Halliday et al 1991). Both single and multiple lesions may occur without other stigmata of neurofibromatosis (Bouldin 1990), but what may appear to be a solitary spinal neurofibroma may be a prodromic lesion of neurofibromatosis (Minckler 1971; Riccardi 1982), particularly in young patients (Sbrocca, Gorini and Artesi 1989).

Solitary spinal neurofibroma is thus a rare tumour which is difficult to classify and to diagnose. We studied four patients with solitary spinal neurofibroma to gain some insight into the diagnostic and therapeutic problems of this tumour and to identify its clinical and pathological characteristics.

\section{PATIENTS AND METHODS}

We studied three men and one woman with a mean age of 41.5 years. The signs and symptoms of neurofibromatosis had been excluded by the history and by examination.

The duration of symptoms and the neurological signs before surgery were recorded. In all patients anteroposterior and lateral radiographs of the spine were obtained; myelography was performed in three patients, CT in three, and MRI in three. Table I shows the clinical details.

Histology and ultrastructure. Pathological tissue from all four tumours was fixed in $4 \%$ formaldehyde in $0.1 \mathrm{M}$ phosphate buffer, $\mathrm{pH} 7.4$, at $4^{\circ} \mathrm{C}$ for 24 hours. One half of each specimen was washed in tap water, dehydrated in graded alcohols, cleared in chloroform, embedded in paraffin, cut transversally and longitudinally into thin sections of 5 to $6 \mu \mathrm{m}$ and stained with haematoxylin and eosin and Masson's trichrome stain. Bielschowsky's method was used for nerve fibres, Gomori and Fulmer stains for fibres and reticulum, and alcian blue for glycosaminoglycans.

The other half of each specimen was fixed in $4 \%$

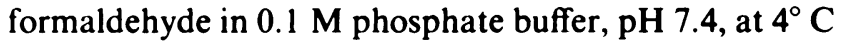
for 12 hours, then sectioned into $1 \mathrm{~mm}$ cubes with a stereomicroscope. These were postfixed in $1.3 \%$ osmium tetroxide, $\mathrm{pH} 7.4$, in Milloig's buffer for one hour, dehydrated first in graded concentrations of ethanol and then in propylene oxide and embedded in Agar 100 epoxide resin (Agar Scientific, Stanstead, UK). Ultrathin $(80$ to $90 \mathrm{~nm})$ sections obtained with a diamondblade ultramicrotome (Ultratome III, LKB, Bromma, Sweden) were mounted on copper grids, stained with lead citrate and uranyl acetate and examined by a transmission electron microscope (Philips EM 400, Philips, Eindhoven, The Netherlands).

\section{RESULTS}

Clinical findings. The first symptom was always vertebral pain with or without radicular pain. Motor deficiency due to nerve root compression was seen in the two patients with lumbar lesions. At follow-up one patient had slight persistent weakness of the extensor digitorum communis of the foot.

Radiographic findings. Radiographic examination of three patients showed evidence of slow compression of the skeletal structures by the expanding lesion. These changes included erosion of the pedicles, increase in the interpedicular distance, distortion of the laminae, enlargement of a neural foramen and localised erosion of the vertebral body. In one tumour of the lumbar spine, the radiographs were negative.

Myelography. There were invariably secondary signs of the presence of the lesion. In two patients there was a characteristic block (Fig. 1), and in one a filling defect with 'amputation' of the root due to intraforaminal spread.

Computerised tomography. The images precisely defined the boundaries of the lesion and the extent of bone erosion and distinguished the typical hour-glass appearance of a tumour with intra- and extraspinal growth (Fig. 2).

Magnetic resonance imaging. On $\mathrm{T} 1$-weighted images the neoplasm showed intensity signals which were slightly higher than those of muscle. There was always an increased T2-weighted signal but with many areas of decreased signal intensity centrally. After injection of gadolinium DTPA contrast, the tumours showed a bright peripheral enhancement and non-uniform contrast enhancement in central areas (Fig. 3).

Surgical treatment. In all patients we performed laminectomy and opening of the dura to expose the neoplasm completely. Unlike neurinoma, spinal neurofibroma

Table I. Details of four patients with solitary spinal neurofibroma

\begin{tabular}{|c|c|c|c|c|c|c|c|c|c|c|c|c|c|}
\hline \multirow[b]{2}{*}{ Case } & \multirow{2}{*}{$\begin{array}{l}\text { Age } \\
\text { (yr) }\end{array}$} & \multirow[b]{2}{*}{ Sex } & \multirow{2}{*}{$\begin{array}{l}\text { History } \\
\text { (mth) }\end{array}$} & \multirow[b]{2}{*}{ Level } & \multirow[b]{2}{*}{ Site } & \multirow[b]{2}{*}{ Pain* } & \multicolumn{2}{|c|}{ Disturbances } & \multirow[b]{2}{*}{ Radiography } & \multirow[b]{2}{*}{ Myelography } & \multirow[b]{2}{*}{ CT } & \multirow[b]{2}{*}{ MRI } & \multirow{2}{*}{$\begin{array}{l}\text { Follow-up } \\
\text { (mth) }\end{array}$} \\
\hline & & & & & & & Motor & Sensory & & & & & \\
\hline 1 & 50 & $\mathbf{M}$ & 7 & D12 & Intradural & + & - & - & + & + & + & + & 36 \\
\hline 2 & 42 & $\mathbf{M}$ & 3 & L4 & Intra/extradural & + & + & + & + & + & + & + & 15 \\
\hline 3 & 35 & $\mathbf{M}$ & 4 & L5 & Intradural & + & + & + & - & + & - & + & 31 \\
\hline 4 & 39 & $\mathbf{F}$ & 9 & C6 & Intradural & + & - & + & + & - & + & - & 59 \\
\hline
\end{tabular}

+ , yes: - , no 
lacks a well-defined capsule and since there is no easily identified cleavage plane careful dissection was necessary to avoid damage to the nerve roots and the radicular artery. The dura was meticulously repaired (Fig. 4).

Macroscopic examination. The tumour was solid, oval in shape and yellowish-brown in colour. It was softer and more elastic than a neurinoma which has a hard rubbery consistency. Fibres of the nerve roots involved lay almost always within the neoplastic parenchyma; by contrast the neurinoma displaces the root without involving it.

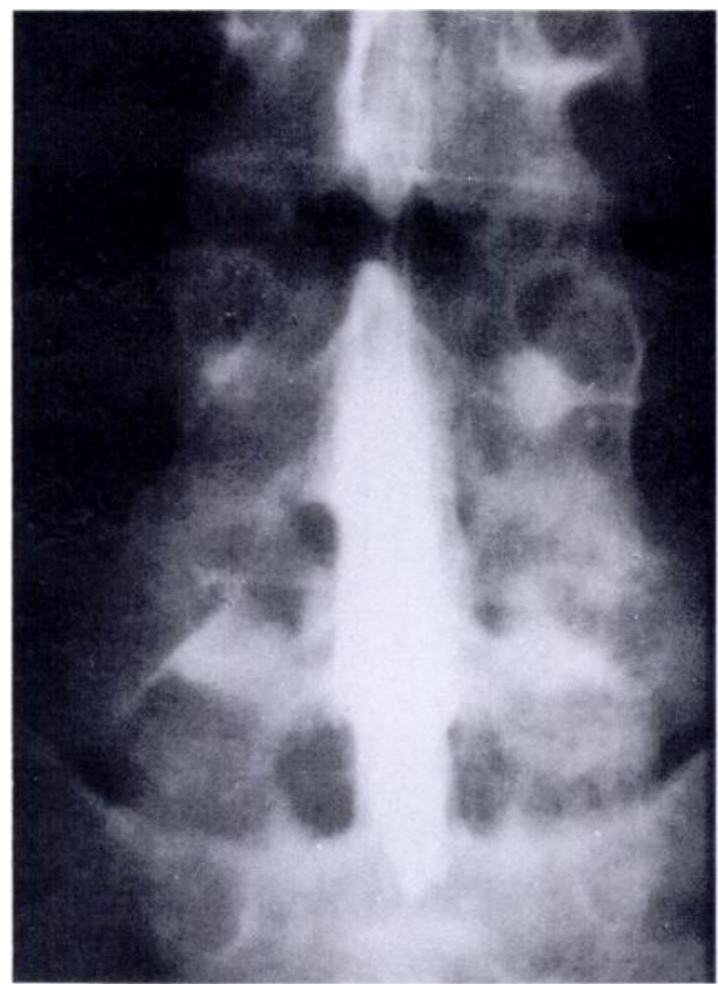

Fig. 1a
Histological examination. Hyperplasia of the interfascicular connective tissue was found in all cases (Fig. 5a). The matrix was rich in proteoglycans and there were numerous tightly packed collagen and reticular fibres. Stenosis was present in the fascicles, which were compressed by the surrounding connective tissue. There was no well-defined capsule. Numerous areas of myxoid degeneration were seen in the proliferating connective tissue and there was hyperplasia of the vascular stroma (Fig. 5b). The predominant cells were elongated with

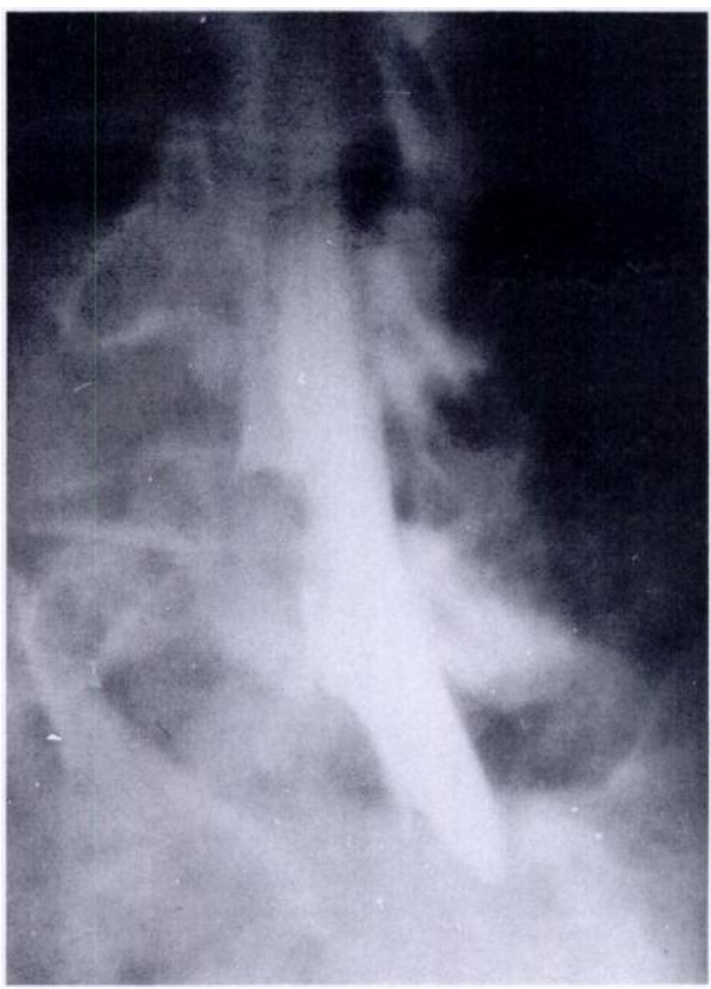

Fig. 1b

Anteroposterior (a) and lateral (b) myelograms showing the secondary signs of a solitary lumbar neurofibroma. The characteristic block suggests intradural and extramedullary tumour growth (case 2).

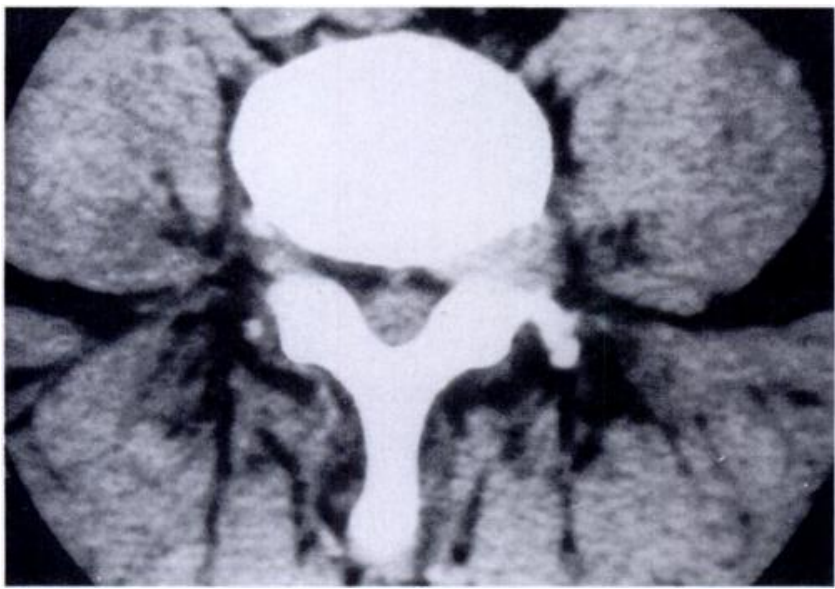

Fig. 2a

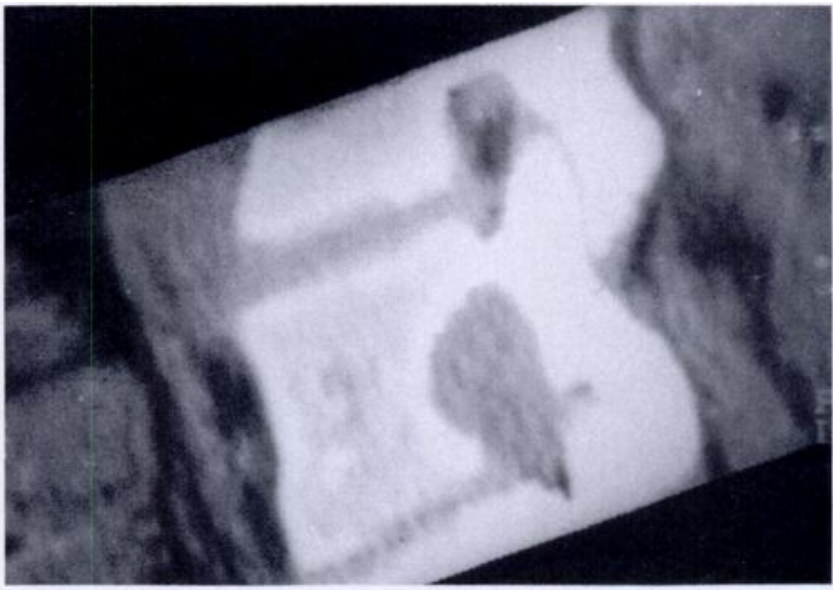

Fig. 2b

Figure 2a - The axial CT image shows widening of the left L3-L4 intervertebral foramen, which is filled by a homogeneous soft-tissue mass. The lesion is slightly higher in attenuation values than the dural sac and the paraspinal soft tissues. Figure $2 b-$ The sagittal image shows the extent of the erosion of the vertebral body and enlargement of the intervertebral foramen (case 2). 
elliptical nuclei. Numerous mast cells located close to and at a distance from the vascular capillaries were identified by the presence of metachromasia.

Ultrastructural analysis. Electron microscopy revealed fewer cells than in a neurinoma. At least three different types were identified: cells resembling Schwann cells, perineurial or fibroblast-like cells, and mast cells.

The Schwann cells had very large nuclei surrounded by dense chromatin, a clear scanty cytoplasm and a pronounced basal lamina (Fig. 6a).

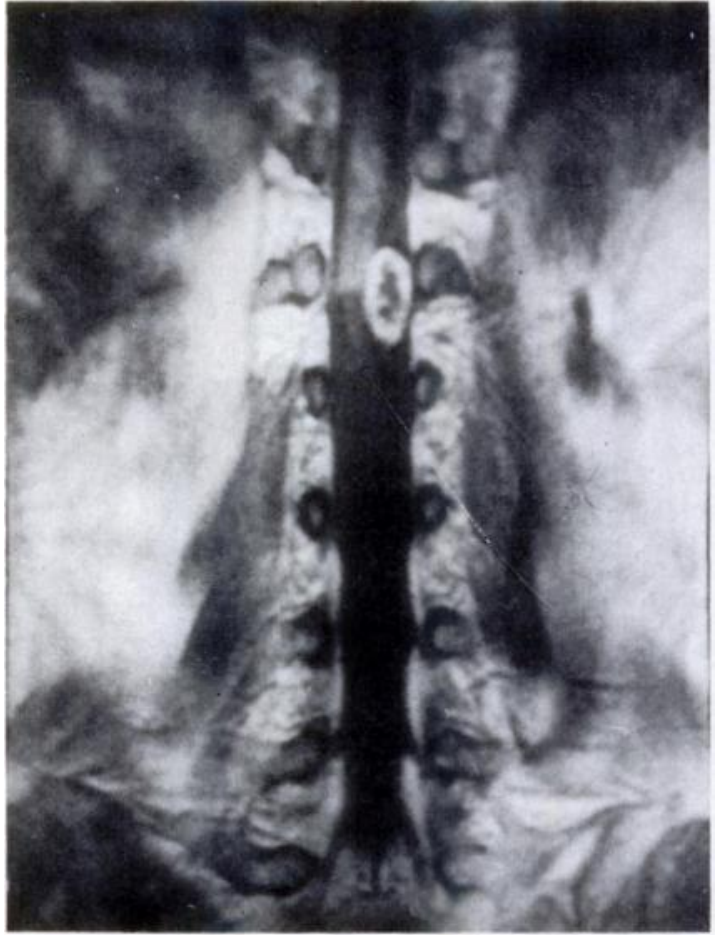

Fig. 3a
The fibroblast-like cells were fusiform with an elongated nucleus and had fine, folded cytoplasmic processes at either end which were frequently electrodense (Fig. 6b), unlike the Schwann cells which always had clear cytoplasm. The perinuclear area of the cytoplasm contained few mitochondria, a scanty folded endoplasmic network and an extensive Golgi apparatus. Microfilaments and microtubules were, however, conspicuously present in the cell processes together with numerous pinocytotic vesicles. The basal lamina was

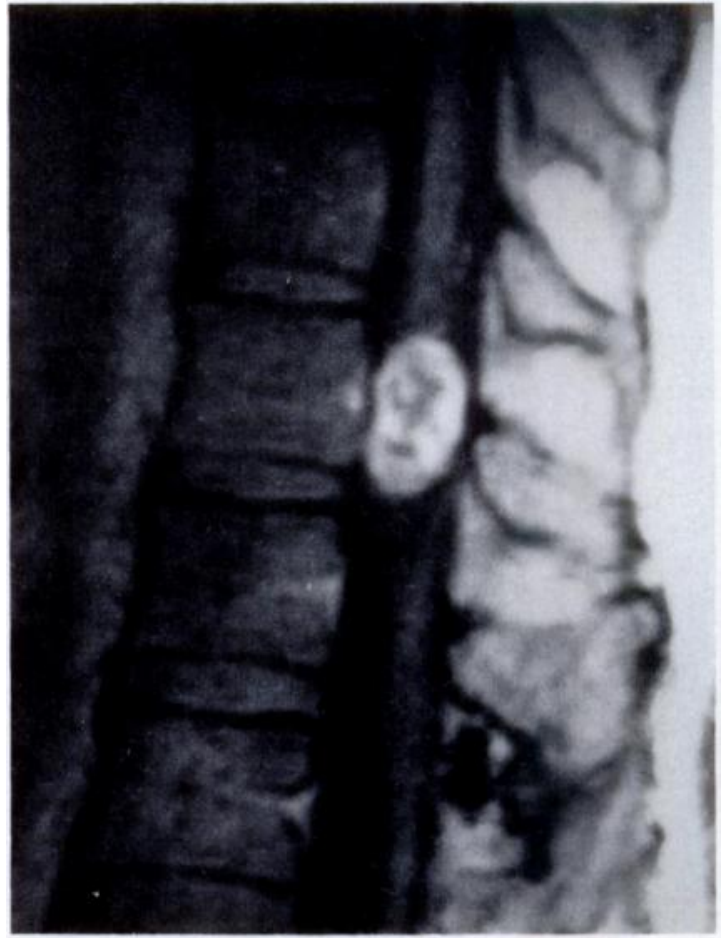

Fig. 3b

MR coronal (a) and sagittal (b) T1-weighted images after injecting gadolinium DTPA show an intradural soft-tissue mass at D12. The mass has intensity signals slightly higher than those of muscle and multiple areas of decreased signal intensity centrally. The CSF below the neurofibroma is more intense than that above due to the increase in the protein concentration in the trapped fluid (case 1).

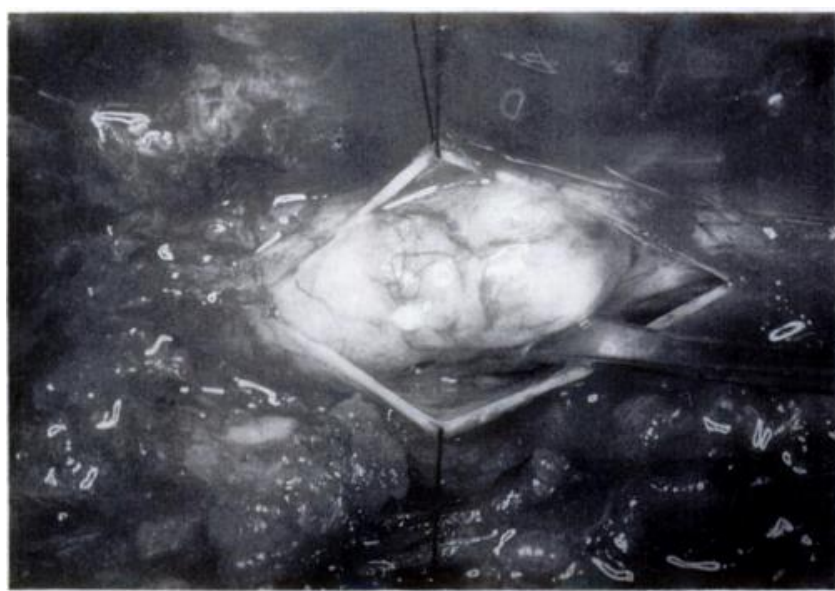

Fig. 4a

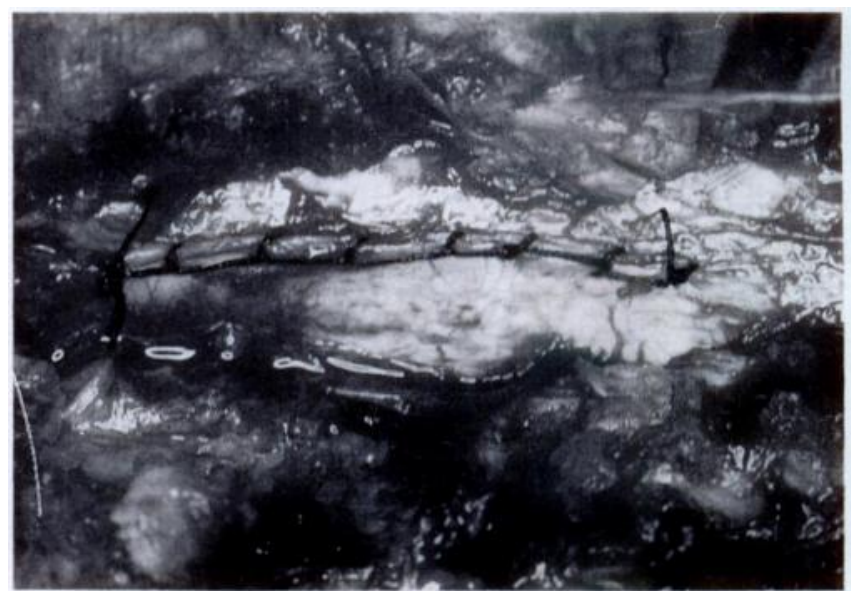

Fig. 4b

The surgical removal of a spinal neurofibroma. Figure 4a - Laminectomy and wide opening of the dura is necessary to expose the neoplasm completely. Figure $4 b$ The dura is meticulously sutured after removal of the mass (case 2). 


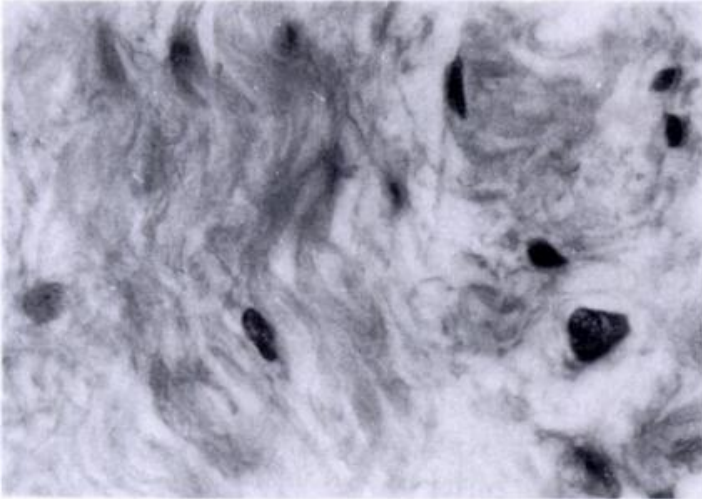

Fig. 5a

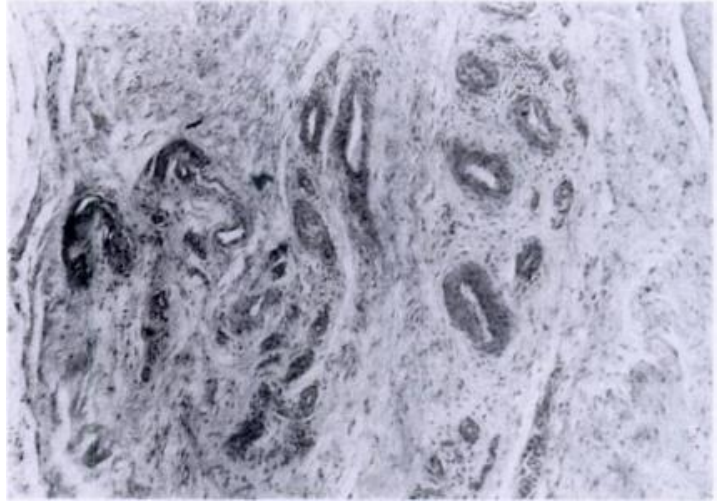

Fig. $5 b$

Figure 5a Histological examination shows hyperplasia of the interfascicular connective tissue. The matrix is rich in proteoglycans and there are numerous tightly packed collagen and reticular fibres. The predominant cells are elongated with elliptical nuclei $(\times 50)$. Figure $5 b-$ There are numerous areas of myxoid degeneration in the proliferating connective tissue and hyperplasia of the vascular stroma $(\times 10)$.

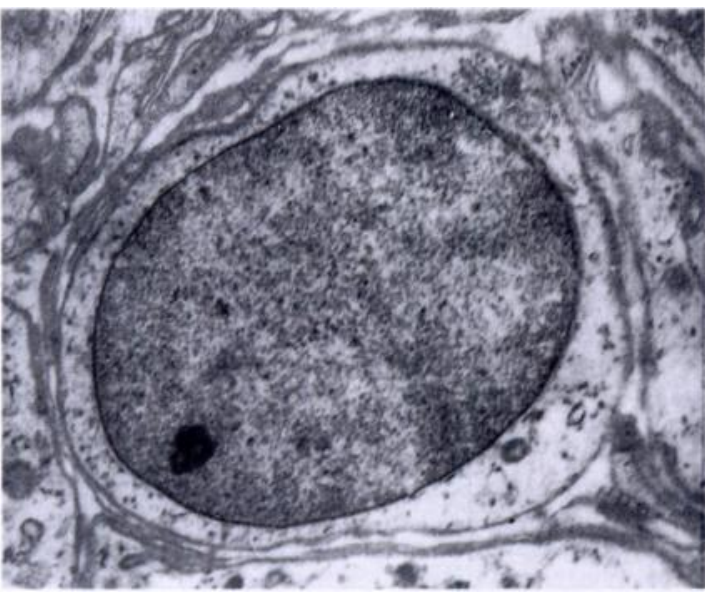

Fig. 6a

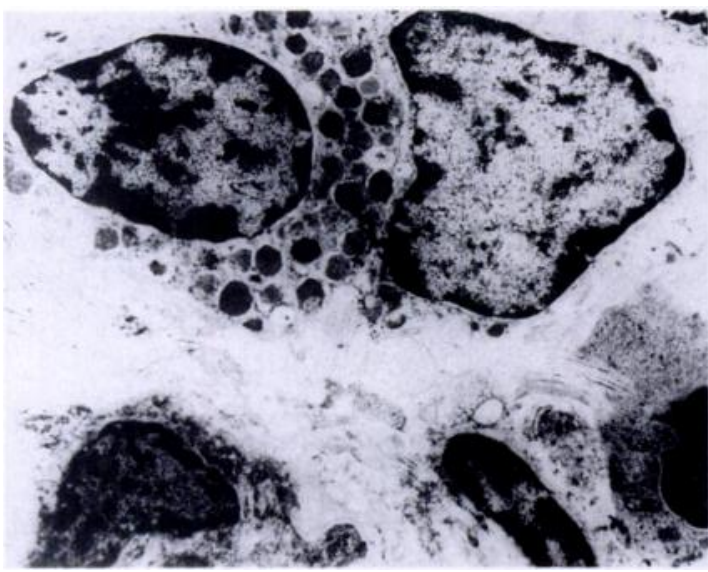

Fig. 6c

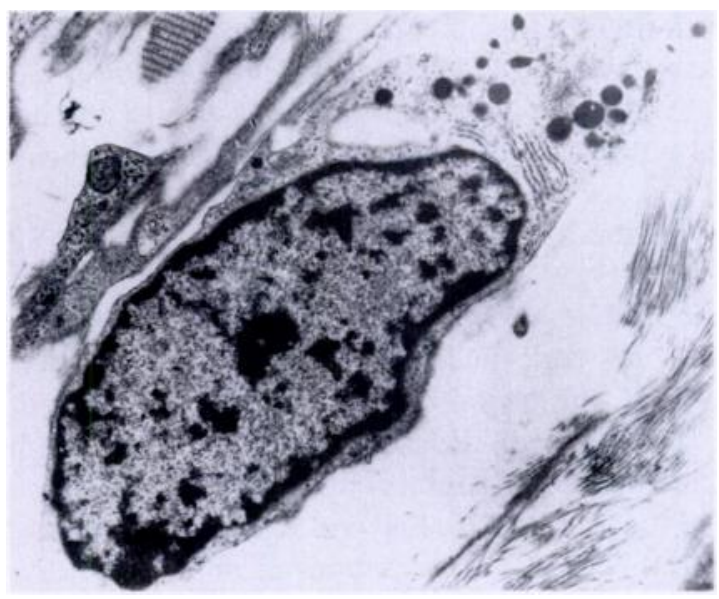

Fig. 6b

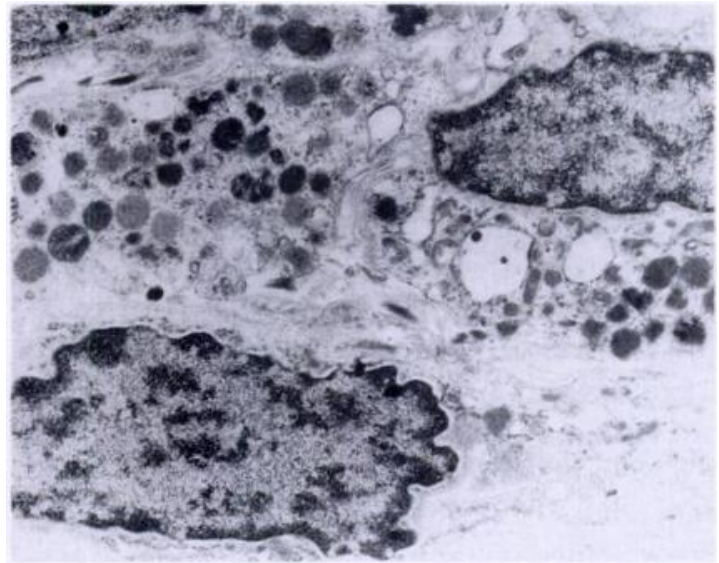

Fig. 6d

Figure 6a - Electron micrograph showing Schwann cells with very large nuclei, dense chromatin surrounding the nuclear membrane, clear scanty cytoplasm and a pronounced basal lamina $(x 10000)$. Figure $6 \mathrm{~b}-$ Fusiform fibroblast-like cells have elongated nuclei and fine, folded cytoplasmic processes at either end. These cytoplasmic processes are often electrodense. The perinuclear area of the cytoplasm contains very few mitochondria, a scanty folded endoplasmic network and an extensive Golgi apparatus. Microfilaments and microtubules are conspicuous in the cell processes together with numerous pinocytotic vesicles. The basal lamina is fragmented or even absent and the extracellular compartment contains numerous collagen fibrils interspersed with areas of myxoid tissue $(\times 6000)$. Figures $6 c$ and $6 d-$ Numerous mast cells arranged near the perineurial cells and at a distance from the Schwann cells. The mast cells can be recognised by their central nuclei, peripherally dense chromatin and numerous intracytoplasmatic electrodense granules. The plasma membrane has short processes which are closely interlocked with the fine elongated processes of the perineurial cells $(\times 4500,5750)$. 
discontinuous, fragmented or even absent and the extracellular compartment contained numerous collagen fibrils variously arranged and interspersed with areas of myxoid tissue.

Mast cells (Figs 6c,d) were relatively numerous and characteristically were arranged near the perineurial cells and at a distance from the Schwann cells. They had a central nucleus with dense peripheral chromatin and numerous intracytoplasmic electrodense granules. The plasma membrane contained short processes which were closely interlocked with the fine elongated processes of the perineurial cells.

\section{DISCUSSION}

Since solitary neurofibroma at any site has been only recently defined as a clinical entity and is still controversial, it is not surprising that there is even more uncertainty and confusion as regards its rare appearance in the spine. As we have already emphasised, the problems are not only due to the confused terminology but also to the absence of a precise clinical and pathological classification.

Some authors (Okazaki and Scheithauer 1988; Sbrocca et al 1989) have claimed that about $90 \%$ of central and peripheral neurofibromas are solitary and are unrelated to systemic neurofibromatosis. Others have suggested that the neurofibroma is the typical and exclusive lesion of von Recklinghausen's disease and even when apparently solitary should be regarded as evidence of that disease (Russell and Rubinstein 1989).

We feel that the many cases reported in the literature of solitary neurofibroma in the absence of neurofibromatosis cannot be ignored (Chomette et al 1984; Noterman, Ballaux and Dor 1984; Okazaki and Scheithauer 1988; Sbrocca et al 1989; Viard et al 1989; Hillstrom, Zarbo and Jacobs 1990) and our observations confirm that although rare, the solitary form of spinal neurofibroma does occur. Moreover, we have identified some radiographic, histological and ultrastructural characteristics which allow differentiation from other neoplastic lesions and from neurinoma in particular.

MRI with its high definition of soft tissues and its ability to obtain multiple plane images allows preoperative differentiation of several types of spinal tumour, particularly of neurinoma, neurofibroma, meningioma and haemangioma (Takemoto et al 1988). In our three cases the T1-weighted image gave a slightly higher signal than muscle and an increased T2-weighted signal but with many central areas where the signal was decreased. After injection of gadolinium DTPA contrast the tumours showed a bright peripheral enhancement and nonuniform contrast in the central areas. Similar observations were reported by Burk et al (1987) in seven patients with spinal neurofibroma in neurofibromatosis and they suggested that these MRI findings were specific to neurofibroma.
The histological findings in our cases explain the CT and MR images. The proteoglycan-rich matrix, the areas of myxoid degeneration and fibroconnective tissue proliferation and the hyperplasia of the vascular stromal component match the tomographic analysis, and the high water content of the neoplastic matrix explains the increased signal in the T2-weighted images. The lack of homogeneity of the signal in the central area can be attributed to the high density of the poorly cellular fibrous tissue within the tumour.

With regard to treatment, some authors have preferred a conservative surgical approach with only partial removal of the tumour if it is intramedullary or involves important nerve roots (Gautier-Smith 1967; Salah, Horcajada and Perneczky 1975; Stein 1985). We agree, however, with Kim et al (1989) that with a wide surgical exposure, radical excision can be achieved without nerve damage. 'False recurrence' has often been described after incomplete removal of the neoplasm (Schiffer and Fabiani 1970) and it is necessary to beware of intradural extension in lesions which are apparently exclusively extradural, because of the frequency of hourglass tumours.

Histological and ultrastructural analysis has demonstrated in the spine those same differences between neurofibroma and neurinoma which we have previously reported in peripheral nerves (Sanguinetti et al 1991). The predominant cell type of the neurofibroma is a perineurial cell with long bipolar or tripolar electrodense cytoplasmic processes, fragmentation of the basal lamina and containing numerous pinocytotic vesicles. If the presence of a more conspicuous amount of loose connective tissue is excluded, there were no histological differences between peripheral and spinal neurofibromas.

Besides the theoretical interest of identifying the solitary spinal neurofibroma as a separate neoplasm, there is also the clinical and prognostic importance. Whereas malignancy can be excluded for a neurinoma (Carstens and Schrodt 1969; Guccion and Enzinger 1979) and is extremely rare for a solitary neurofibroma (Okazaki and Scheithauer 1988) it is nevertheless quite common in multiple neurofibromas (Stout 1958; Poirier et al 1968; Russell and Rubinstein 1989).

No benefits in any form have been received or will be received from a commercial party related directly or indirectly to the subject of this article.

\section{REFERENCES}

Adair FE, McLean J. Tumors of the peripheral nerve system: with a report of 2782 cases. In: Tumors of the nervous system. Assoc Res Nerv Ment Dis Res Pubs XVI. Baltimore: Williams \& Wilkins 1937:440-64.

Bouldin TW. Nerve biopsy. In: Garcia JH, Escalona-Zapata J, Sandbank U, Cervós-Navarro J, eds. Diagnostic neuropathology. Vol. 2. Berlin, etc: Springer-Verlag, 1990:123-202.

Burk DL, Brunberg JA, Kanal E, Latchaw RE, Wolf GL. Spinal and paraspinal neurofibromatosis: surface coil MR imaging at $1.5 \mathrm{~T} 1$. Radiology 1987; 162:797-801. 
Carstens PHB, Schrodt GR. Malignant transformation of a benign encapsulated neurilemoma. Am J Clin Path 1969; 51 :144-9.

Catalano F, Fanfani F, Mazzone V. PIl fibroma interstiziale del nervo. Mineria Ortopedica 1985; $36: 893-7$.

Chomette G, Auriol M, Tranbaloc P, Bertrand JC. Schwannomes et neurofibromes de la région cervico-faciale. Arch Anat Cytol Path 1984: 32:69-76

Enzinger FM, Weiss SW. Soft tissue tumors. St Louis, etc: CV Mosby Co, 1983:705-19.

Erlandson RA, Woodruff JM. Peripheral nerve sheath tumors: an electron microscopic study of 43 cases. Cancer 1982; 49:273-87.

Gautier-Smith PC. Clinical aspects of spinal neurofibromas. Brain 1967; 90:359-94.

Guccion JG, Enzinger FM. Malignant schwannoma associated with von Recklinghausen's neurofibromatosis. Virchows Archiv A (Pathol Anat) 1979: 383:43-57.

Halliday AL, Sobel RA, Martuza RL. Benign spinal nerve sheath tumors: their occurrence sporadically and in neurofibromatosis Types 1 and 2 . J Neurosurg $1991: 74: 248-253$.

Harkin JC. Pathology of nerve sheath tumors. Ann NY Acad Sci 1986; 486:147-54

Hertzog P, Toty L, Personne CI, Colchen A, Belami J. Tumeurs nerveuses du thorax. Ann Chir 1980; $34: 251-6$.

Hillstrom RP, Zarbo RJ, Jacobs JR. Nerve sheath tumors of the paranasal sinuses: electron microscopy and histopathologic diagnosis. Otolaryngol Head Neck Surg 1990; 102:257-63.

Kim P, Ebersold MJ, Onofrio BM, Quast LM. Surgery of spinal nerve schwannoma : risk of neurological deficit after resection of involved root. J Neurosurg 1989: 71 :810-4.

Lhermitte J, Leroux R. Étude histologique générale des gliomes des nerfs périphériques, des racines rachidiennes et des gliomes viscéraux. Rev Neurol 1923; 30:286-94.

Masson P. Tumeurs humaines: histologie, diagnostics et techniques. Second ed. Paris: Libraire Maloine, 1968

Minckler J. Supporting cell tumors of peripheral nerves. In: Minckler J, ed. Pathology of the nervous system. Vol. II. New York, etc: McGraw-Hill Book Company, 1971 :2093-2114

Nittner K. Spinal meningiomas, neurinomas and neurofibromas and hourglass tumours. In: Vinken PJ and Bruyn GW, eds. Handbook of clinical neurology. Vol. 20. Amsterdam, etc: North-Holland Publishing Company, 1976:177-322.

Noterman J, Ballaux JM, Dor P. Tumeur nerveuse cervicale: à propos d'un cas. Acta Chir Belg 1984; 357-9.
Okazaki H, Scheithauer B. Atlas of neuropathology. New York: JB Lippincott Company, 1988:201-6.

Penfield W, Young AW. The nature of von Recklinghausen's disease and the tumors associated with it. Arch Neurol Psychiat (Chic) $1930 ; 23: 320-44$.

Poirier J, Escourolle R, Castaigne P. Les neurofibromes de la maladie de Recklinghausen : étude ultrastructurale et place nosologique par rapport aux neurionomes. Acta Neuropath 1968; 10:279-94.

Riccardi VM. Neurofibromatosis: clinical heterogeneity. Curr Probl Cancer 1982; 7:1-34.

Russell DS, Rubinstein LJ. Pathology of tumours of the nerious system. 5th ed. London, Edward Arnold, 1989; 533-71.

Salah S, Horcajada J, Perneczky A. Spinal neurinomas: a comprehensive clinical and statistical study on 47 cases. Neurochirurgia 1975; 18:77-84.

Sanguinetti C, de Santis E, Rosa MA. I neurinomi vertibrali. Arch Putti Org Mor 1981:31:305-16.

Sanguinetti C, Greco F, de Palma L, et al. Morfologcia ultrastrutturale dei neurinomi e neurofibromi dei nervi periferici. Giorn Ital Ortop Traum 1991; $26: 245-54$.

Sbrocca M, Gorini E, Artesi L. I neurofibromi delle logge laterocervicali : quattro casi personali. Acta Otorhinolaryngol Ital 1989; 9:521-6.

Schiffer D, Fabiani A. Patologia dei tumori cerebrali. Rome: Il Pensiero Scientifico Editore, 1970.

Stein BM. Spinal intradural tumors. In: Wilkins RH, Rengachary SS, eds. Neurosurgery. New York. etc: McGraw-Hill Book Company, 1985:1048-61.

Stout AP. Tumors of the peripheral nerves. J Bone Joint Surg [Am] $1958 ; 40-A: 959$.

Takemoto K, Matsumura $Y$, Hashimoto $H$, et al. MR imaging of intraspinal tumors: capability in histological differentiation and compartmentalization of extramedullary tumors. Neuroradiology $1988 ; 30: 303-9$.

Tarlov IM. Origin of perineural fibroblastoma. Am J Path 1940; 16: 33-40.

Verocay J. Zur Kenntnis der Neurofibrome. Ziegl Beitr 1910; 48:1-69.

Viard H, Sautreaux JL, Haas $O$, et al. Tumeurs nerveuses en sablier. Chirurgie 1989; $115: 521-5$.

von Recklinghausen F. Ueber die multiplen Fibrome der Haut und ihre Beziehung zu den multiplen euromen. Berlin: Verlag von August Hirschwald, 1882.

Zülch KJ. Brain tumors: their biology and pathology, 2nd ed. New York: Springer, 1965. 